
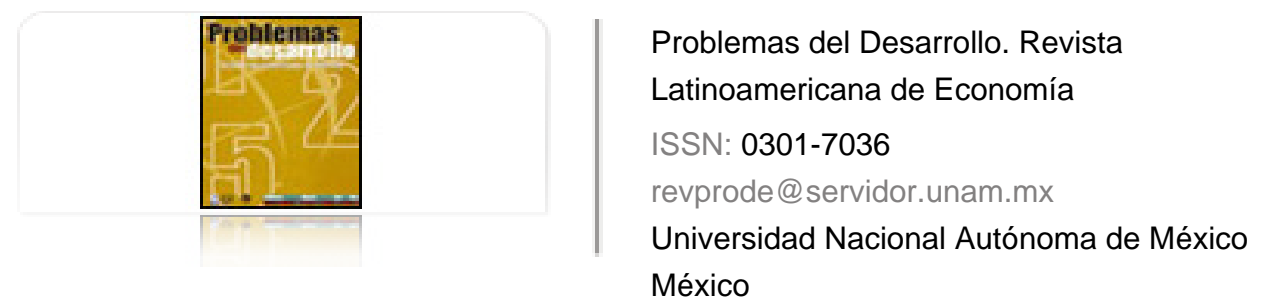

Guerra-Borges, Alfredo

Regionalismo y multilateralismo en su laberinto

Problemas del Desarrollo. Revista Latinoamericana de Economía, vol. 39, núm. 152, enero-marzo, 2008, pp. 11-28

Universidad Nacional Autónoma de México

Distrito Federal, México

Disponible en: http://www.redalyc.org/articulo.oa?id=11820668002

- Cómo citar el artículo

- Número completo

- Más información del artículo

Página de la revista en redalyc.org

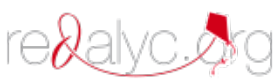

Sistema de Información Científica

Red de Revistas Científicas de América Latina, el Caribe, España y Portugal Proyecto académico sin fines de lucro, desarrollado bajo la iniciativa de acceso abierto 


\title{
REGIONALISMO Y MULTILATERALISMO EN SU LABERINTO
}

\author{
Alfredo Guerra-Borges*
}

Fecha de recepción: 26 de marzo de 2007. Fecha de aceptación: 27 de octubre de 2007.

\section{Resumen}

Después de un periodo de oscurecimiento, en especial la integración económica, el regionalismo ha vuelto a despertar un enorme interés tanto en el medio académico como en el nivel institucional internacional. Hay diversas explicaciones de lo anterior y este trabajo se detiene a considerarlas. El artículo destaca la transformación profunda -normativa e institucional, que se ha conocido en los años ochenta y noventa del siglo pasado- provocada por la globalización. En este aspecto se postula una definición original que, más allá de sus múltiples expresiones, sobre todo en la economía, se centra esencialmente en el fenómeno como proceso histórico. La diseminación mundial del regionalismo ha dado lugar a un debate sobre la relación que guardan el regionalismo y el multilateralismo, cuestión que ha llegado a ser compleja y desafiante por lo que requerirá un tratamiento especifico y más adelante se integrará al esbozo que ahora se deja planteado.

Palabras clave: regionalismo, nuevo regionalismo, regionalismo abierto, multilateralismo.

* Investigador del Instituto de Investigaciones Económicas, UNAM. Correo electrónico: alfredo@servidor.unam.mx. 


\section{Summary}

After a period of obscurity, especially for economic integration, regionalism has again awoken an enormous amount of interest both at an academic and international institutional level. There are several explanations for this and the present work pauses to consider them. The study stresses the profound transformation-normative and institutional, evident during the 1980s and 1990s — caused by globalization. On this question, it proposes an original definition which, beyond its multiple expressions, above all in the economy, focuses essentially on the phenomenon as a historical process. The worldwide dissemination of regionalism has given rise to a debate on the relationship between regionalism and multilateralism, a question that has come to be complex and challenging, and which will therefore require a specific treatment later to be integrated into the sketch that has already been made.

Key words: regionalism, new regionalism, open regionalism, multilateralism.

\section{Résumé}

Après une période d'assombrissement notamment en ce qui concerne l'intégration économique, le régionalisme réveille de nouveau un énorme intérêt tant dans les milieux académiques que chez les institutions internationales. Il y a plusieurs explications à cela et ce travail les prend en considération. L'article souligne la profonde transformation - normative et institutionnelle - connue dans les années 80 et 90 du XXe et provoquée par la mondialisation. Il est ainsi proposé une définition originale qui, au-delà de ses multiples manifestations notamment sur le plan économique, aborde le phénomène essentiellement en tant que processus historique. La dissémination mondiale du régionalisme a donné lieu à un débat sur la relation que gardent le régionalisme et le multilatéralisme, question devenue complexe dont la compréhension représente un défi, laquelle requière un traitement spécifique et sera intégrée plus loin à ce schéma général.

Mots clés: régionalisme, nouveau régionalisme, régionalisme ouvert, multilatéralisme.

\section{Resumo}

Depois de um período de obscurecimento, em especial a integração econômica, o regionalismo voltou a despertar um enorme interesse tanto no meio acadêmico como a nível institucional internacional. Há diversas explicações do anterior e este trabalho detém-se a considerá-las. $O$ artigo destaca a transformação profunda - normativa e institucional, que se conheceu nos anos oitenta e noventa do século passado - provocada pela globalização. Neste aspecto postula-se uma definição original que, mais além de suas múltiplas expressões, principalmente na economia, centra-se essencialmente no fenômeno como processo histórico. A disseminação mundial do regionalismo deu lugar a um debate sobre a relação que guardam o regionalismo e o multilateralismo, questão que chegou a ser complexa e desafiante pelo que requererá um tratamento especifico e mais adiante integrar-se-á ao esboço que agora se deixa proposto.

Palavras chave: regionalismo, novo regionalismo, regionalismo aberto, multilateralismo. 


\section{Introducción}

$\mathcal{E}$

n los años noventa del último siglo la implosión de la Unión Soviética puso fin

a la guerra fría. De la confrontación de dos sistemas se pasó a la universalización del capitalismo. Contrariamente a lo que podía esperarse, la característica fundamental del nuevo orden mundial no fue su invariabilidad por predominio total del capitalismo sino su contrario, la mutabilidad. No obstante la soledad soberana del capitalismo, el tránsito se operó de la estabilidad bipolar de dos superpotencias a la inestabilidad sistémica del mundo multipolar. Se pasó de la bipolaridad concentrada a la multipolaridad difusa (Mistry, 1999).

En el nuevo ambiente, impreso con todas las características de la nueva globalización, cuyos cimientos se echaron a raíz de la crisis mundial de los años setenta, se operó una rápida apertura externa de numerosos países en desarrollo, notablemente en América Latina, impulsada por los "ajustes estructurales" del Banco Mundial (BM) y el Fondo Monetario Internacional (FMI), la "doble condicionalidad" que presidió el otorgamiento de nuevos préstamos, y por la obligada aplicación de los preceptos del Consenso de Washington. La apertura unilateral que resultó de todo aquello se tradujo en la facilitación de la concertación de numerosos acuerdos de libre comercio. Transformado el contexto mundial cambió también el contenido, menos de lo que se piensa, de lo que desde entonces se denomina nuevo regionalismo.

Al mismo tiempo el multilateralismo realizó avances notables, sobre todo la conclusión de la Ronda Uruguay y la creación de la Organización Mundial del Comercio (OMC). Lo que permanece sin cambios en esta institución es el concepto que se tiene desde hace 50 años de la relación entre el regionalismo y el multilateralismo. La hipótesis que se plantea en este trabajo es que esa relación debe ser reconceptualizada.

\section{Delimitación de conceptos}

En este trabajo se usarán discriminadamente los términos regionalismo y regionalización, pues conceptualmente no son idénticos. Como lo indica el sufijo "ismo" (ism en inglés) debe entenderse por regionalismo la tendencia a crear regiones integradas, en tanto que la regionalización es el resultado de la acción de regionalizar, como son los acuerdos preferenciales, comerciales bilaterales, regionales e interregionales. Aun así el término resulta inexacto, pues no todos los convenios concertados comprenden regiones, y el concepto mismo de región es ambiguo, no obstante que es muy utilizado raras veces está claramente definido (Buzan, 1998). 
Tan imperfecta como lo anterior es la simplificación que ha hecho la OMC de la diversidad de los acuerdos al denominarlos genéricamente Acuerdos Regionales de Comercio (RTA, por sus siglas en inglés). Sin embargo, es forzoso rendirse ante las exigencias de la exposición, que resultaría muy engorrosa si se pretendiera ser muy puntilloso en esta materia. Se tratará de ajustarse lo más posible a los significados menos imperfectos pero más de una vez se recurrirá inclusive a acrónimos (ACR en este trabajo).

El multilateralismo es más ambiguo. Así Alan Winters declara que no definirá este concepto precisamente porque no encuentra que pueda hacerlo fácilmente. Argumenta que, no obstante ser el multilateralismo una característica del sistema económico mundial, es en el desempeño de cada país donde finalmente debe estar presente, en la medida que las naciones se conducen de modo multilateral. Esto último se trata como una función del grado en que la discriminación está ausente, en que el régimen comercial de cada país se aproxima al libre comercio (Winters, 1996).

No se ve así. Sin duda la elección del libre comercio por un país lo inclina a suscribir acuerdos multilaterales, pero no siempre está presente el libre consentimiento de las naciones, sino más bien, con mucha frecuencia, el temor a lo que podría sobrevenirle de no estar allí. El multilateralismo no es una asamblea del libre albedrío. Aquí se utilizará el término en las dos acepciones que, desde el punto de vista de este trabajo, tiene en los hechos, como multilateralismo realmente existente, o sea, el multilateralismo institucionalizado en la OMC; o bien en su acepción ideal según la cual la liberalización no discriminatoria del comercio internacional eleva el bienestar mundial, que es la idea subyacente en el debate sobre regionalismo y multilateralismo desde hace medio siglo.

El regionalismo y el multilateralismo realmente existente son, en su alcance y características, productos de la globalización. Aquí se conceptualiza la globalización o mundialización indistintamente, no obstante la sutileza de los argumentos para diferenciarlos, como proceso histórico, como proceso civilizatorio de alcance mundial del capitalismo que engloba y explica los hechos y procesos en que se manifiesta y por los cuales se le define habitualmente (internacionalización de la producción, flujos crecientes de capital, el aumento del volumen y la variedad del comercio internacional de bienes y servicios, etcétera) (OCDE, 1992; Dunning, 1994; Oman, 1996, CEPAL, 1996, FMI, 1997). Como proceso histórico la mundialización es el proceso mediante el cual el capitalismo reestructura la economía y las instituciones de toda naturaleza en consonancia con el establecimiento de un nuevo régimen de acumulación, cuya base material es la actual revolución científica y tecnológica.

Este trabajo tiene dos partes. La primera se refiere y analiza el nuevo regionalismo de los países en desarrollo y el de las potencias comerciales, concluyendo con algunas 
observaciones críticas. La segunda se consagrará a la controversia sobre regionalismo y multilateralismo y la comprobación de la hipótesis antes mencionada.

\section{El nuevo regionalismo}

Con el influjo de la mundialización, los países en desarrollo, con mayor precipitación los de América Latina, emprendieron desde los años ochenta, y principalmente en los noventa del siglo pasado, una acelerada liberalización unilateral, y como subproducto de ésta los gobiernos concertaron múltiples acuerdos de libre comercio en muy corto tiempo. De la mano de ese proceso también se liberalizaron los regímenes de inversión y un número significativo de naciones le concedió además trato nacional a la inversión extranjera (Burki y Perry, 1997).

Por el mismo tiempo terminó exitosamente la Ronda Uruguay, de negociaciones comerciales. El multilateralismo alcanzaba así una victoria indiscutible que fue coronada con la creación de la OMC en 1994. Los países en desarrollo, resueltamente inclinados hacia la liberalización comercial, no demoraron en solicitar su ingreso a la OMC. No bastaba con su liberalización, tenían que complementarla con su membresía en la organización para que tuviera credibilidad a los ojos del mundo desarrollado y despertara la confianza de sus inversionistas.

El resultado de lo anterior fue paradójico. A todas luces era contradictorio el auge de los acuerdos de integración (opción restrictiva del multilateralismo) y el ingreso masivo a la OMC (opción multilateralista). Entonces apareció el regionalismo abierto que para Bergsten (1997) constituía una forma de alcanzar el mejor de los mundos: preservar los beneficios de la liberalización regional sin arriesgar la vitalidad del sistema multilateral. La ambigüedad del regionalismo abierto favoreció su pasajera popularidad. Sin embargo, dicha indeterminación fue lo que conspiró contra él. Debía traducirse en una estrategia política pero no la consiguió jamás. Puesto a prueba terminó por no convencer a nadie, y se le olvidó. La conciliación de los dos mundos que con ese concepto se creyó alcanzar cedió el lugar a la reanudación del ser o no ser del regionalismo y el multilateralismo.

$\mathrm{Al}$ ingresar a la OMC los países en desarrollo esperaban realizaciones importantes. Esa confianza perduraba diez años después al convocarse la Conferencia Ministerial de Doha, que abría un nuevo ciclo de negociaciones, esta vez para perfeccionar y llevar adelante los acuerdos de la Ronda Uruguay. El fracaso de las negociaciones en Cancún en 2003 puso fin a las expectativas. Las posiciones de las principales potencias se mostraron irreductibles, y los países en desarrollo, olvidando sus viejos hábitos de aceptar todo lo que las primeras proponían, presentaron un frente muy 


\section{6}

ALFREDO GUERRA-BORGES

cohesionado. Nuevos esfuerzos por desempantanar las negociaciones tuvieron el mismo resultado negativo. Y la opción del regionalismo se fortaleció.

Entonces ahora se verán cuáles son las principales características de los acuerdos comerciales regionales y las principales motivaciones que han tenido para formarse. Esto tiene una importancia fundamental para la discusión sobre la relación existente entre la OMC y el nuevo regionalismo.

\section{Motivaciones}

No obstante su gran diversidad, todos los acuerdos regionales tienen en común el objetivo de reducir las barreras al comercio entre los países miembros, y no es frecuente encontrar referencias sobre políticas de acuerdos regionales que discrimen groseramente a terceras naciones. El regionalismo se utiliza como medio para ampliar el proyecto comercial más allá de lo que en la actualidad permite el sistema comercial multilateral. Algunos acuerdos tienen un sobresaliente dinamismo interno, como lo pone de manifiesto la importancia creciente de su comercio intrarregional, que puede ser superior a la tasa de expansión de sus exportaciones al resto del mundo. En su conjunto el comercio intrarregional de los acuerdos Sur-Sur representa 13\% del comercio mundial y $42 \%$ de la exportación total de todos los países en desarrollo. Sin embargo, este resultado se debe, principalmente, a un número limitado de naciones, sobre todo las del este y sureste de Asia.

La experiencia induce a los países a sentir preferencia por los acuerdos regionales, pues perciben claramente que es más fácil negociar en bloques más pequeños y flexibles que alcanzar el consenso de un centenar y medio de miembros de la OMC; pero además los acuerdos comerciales regionales tienen la virtud de ser más específicos en la consideración de las necesidades de una región en particular, lo que representa una ventaja indudable sobre las soluciones del tipo "menor denominador común" que a menudo ofrecen las negociaciones en la OMC.

De igual manera la experiencia ha mostrado a los países en desarrollo que la concertación de acuerdos regionales de integración es un instrumento insustituible en las negociaciones con terceras naciones o con otros acuerdos y regiones. Un poderoso ejemplo de lo anterior es la experiencia del MERCOSUR. Frente a la negativa inflexible de Estados Unidos para hacer concesiones en la negociación del Área de Libre Comercio de las Américas (ALCA), en particular en cuanto a las subvenciones estadounidenses a las exportaciones al MERCOSUR, éste mantuvo con firmeza su oposición a suscribir el ALCA en tan desventajosas condiciones.

Para los países en desarrollo es evidente que sus intereses pueden estar mejor servidos mediante la integración regional con otras naciones que tienen economías 
similares y, particularmente, con las que tienen afinidad en su enfoque de los problemas afines. Es común a esas naciones la búsqueda de mercados más grandes que los estrechos nichos internos, lo que guarda relación con el atractivo que tiene la liberalización discriminatoria para los países que buscan obtener beneficios del comercio de productos que no son competitivos internacionalmente. Economías pequeñas como las de Centroamérica son uno de los mejores testimonios. Suscrito el Tratado Multilateral de Libre Comercio e Integración Centroamericana en 1958 y el Tratado General de Integración Centroamericana en 1960, la unión aduanera establecida en el curso de los primeros cinco años hizo posible que el comercio intrarregional, principalmente de productos industriales ( $90 \%$ del comercio intrarregional), creciera en el primer decenio a una tasa superior a 20\% (a precios constantes) y un poco menor en los años setenta, en ambos casos a una tasa superior al crecimiento del Producto Interno Bruto (PIB) de la región centroamericana y de las exportaciones al resto del mundo.

Para muchos países en desarrollo la participación en acuerdos regionales es una medida defensiva que les permite mantener abierta las oportunidades de acceso a otros mercados sin tener que ceñirse a la cláusula de nación más favorecida y de trato recíproco. La vecindad geográfica es otra motivación importante pues estimula el intercambio de bienes y servicios, permite atraer inversiones y reduce los costos de transporte. No menos importancia tiene el hecho de que el nivel de eficiencia y de competitividad puede ser robustecido mediante formas de desregulación regional.

Un rasgo importante es que en vista de la pérdida de dinamismo de la OMC los países están convirtiendo los acuerdos regionales en un objetivo central de su política comercial e incluso en algunos de ellos esa prioridad puede llegar a ser superior a la concedida a los objetivos del comercio multilateral.

Finalmente, una tendencia reciente del nuevo regionalismo de los países en desarrollo es suscribir acuerdos de mayor complejidad, superar la etapa de las formas simples de integración e incluir en los acuerdos regionales algunas materias y regulaciones que no necesariamente se ajustan a las disposiciones de la OMC. Esta tendencia se manifiesta hasta ahora de forma incipiente y, como se comprende, corresponde a naciones que tienen un determinado nivel de desarrollo.

\section{Comentarios}

En la abundante literatura que hay en la actualidad sobre regionalismo es usual presentar la pujanza de los acuerdos regionales de comercio aludiendo a su número alrededor de unos 300, y a su participación en el comercio mundial de un poco más de $40 \%$, pero no debe perderse de vista que "los grandes números" revelan el 


\section{8}

ALFREDO GUERRA-BORGES

resultado de una tendencia pero no su composición. En primer lugar, hay grandes diferencias de calidad de los acuerdos y en este sentido es conveniente tener presente que $84 \%$ de los acuerdos son zonas de libre comercio, una forma primaria de la integración regional.

Una inexcusable observación crítica cabe hacer sobre el hecho de que el elevado número de acuerdos de integración comercial ha originado numerosas superposiciones y esto da lugar a mucha confusión en la aplicación de los convenios; además los niveles de las preferencias otorgadas son muy diferentes, las normas de origen difieren notablemente y son distintas también las fechas de terminación de los plazos para alcanzar el perfeccionamiento de los acuerdos, es decir, las fechas en que se alcanza la desgravación cero intrarregional.

En suma, participar en numerosos acuerdos regionales representa una enorme carga administrativa para los países en desarrollo, pues demanda el empleo de numerosos expertos que en estas naciones es uno de los recursos escasos. Un esfuerzo para consolidar varios convenios en agrupaciones mayores sería bienvenido, y es aconsejable que la opción se tuviera presente, aunque se debe reconocer que en muchos casos las condiciones no están dadas para intentarlo.

Por último, una alusión a un aspecto de importancia crucial en el análisis del regionalismo y particularmente para explicar sin menosprecio por qué muchos de los acuerdos Sur-Sur muestran resultados comparativamente más modestos. Se habla del número posiblemente significativo de convenios cuyos países miembros tienen deficiencias estructurales profundas que no les permite aprovechar el potencial de crecimiento y desarrollo de los acuerdos que suscriben. No es materia que corresponda a este artículo su examen detenido, pero parece inexcusable dejar de mencionarlo pues lo que se tiene en mente es el debate sobre regionalismo y multilateralismo. Efectivamente, cuando se reitera la vieja demanda ideológicamente inspirada de multilateralización del regionalismo la desigualdad de subdesarrollos se pasa por alto, no obstante que no todos los países, sino sólo un número pequeño de ellos puede prescindir de sus acuerdos regionales para sumergirse en la normatividad de la OMC, que sigue siendo el mundo normativo de las naciones desarrolladas.

\section{El nuevo regionalismo de las potencias comerciales}

La razón para hacer una diferencia del regionalismo de las potencias comerciales y el de los países en desarrollo es que a éstos su elección del regionalismo se la dicta el subdesarrollo, mientras que la elección de las potencias comerciales se lo dicta el alto nivel alcanzado por su desarrollo. Son esas potencias las que tienen la mayor 
concentración de conocimiento, y es éste el que mueve en la actualidad el comercio mundial y enfrenta a las economías desarrolladas en la búsqueda de nuevos espacios para dar salida a una producción de elevado costo de investigación, para la cual el mundo se les ha empequeñecido.

Con la desaparición de la Unión Soviética se operó el tránsito fundamental de la era de la geopolítica a la era de la geoeconomía y en ésta el regionalismo para fines económicos depende de la lógica del capital global (Inotai, 2000). La Organización para la Cooperación y el Desarrollo Económicos (OCDE) ha sido muy explícita en indicar que la globalización podría definirse como un sistema de producción en el que una fracción cada vez mayor del valor y la riqueza es generada y distribuida mundialmente por un conjunto de redes privadas relacionadas entre sí y manejadas por grandes empresas transnacionales que constituyen estructuras concentradas de oferta (OCDE, 1992). El nuevo orden económico mundial emerge de una recomposición internamente contradictoria de la economía internacional, cuya causalidad profunda es la revolución de las tecnologías y su actor principal, las empresas transnacionales. Son éstas las que en el contexto de su estrategia de internacionalización de la producción integran en un gran conjunto el comercio, la tecnología y los flujos financieros. Como lo dejó indicado Naciones Unidas hace algunos años, "en una economía mundial cada vez más integrada, las corporaciones transnacionales han devenido en organizadoras centrales de la actividad económica" (United Nations, 1992:1).

Ése es el mundo de la globalización de la competencia, pero no de la "libre" de que se habla con un rezago de 200 años, sino de la competencia internacional oligopólica, la de las gigantescas compras y fusiones de oligopolios que pugnan entre sí y han segmentado el mundo en esferas de mercado de equilibrio precario. Para salir con suerte de la contienda las decisiones no pueden ser delegadas en las grandes empresas, la cuestión es demasiado importante para dejarla a su cuidado exclusivamente, hace falta la política. Ahora bien, la globalización de la actividad corporativa ha sido estimulada no sólo por el advenimiento de las nuevas tecnologías de la información, sino también en gran medida por la desregulación del Estado, lo que ha debilitado el control nacional de su economía. En esa erosión del control económico nacional los Estados industriales buscan compensarla por medio de los esquemas de integración regional (Katzenstein, 1996). Sin embargo, esa compensación ya no es sólo mediante acuerdos comerciales, sino con convenios que incluyen las grandes normalizaciones que demanda su enorme poder económico y tecnológico (inversión, derechos de propiedad intelectual, servicios...), a fin de que la competencia entre las firmas 
astronómicas no quede librada a la decisión unilateral de los Estados y se retorne, en una dimensión mayor, a la costosa experiencia de los años treinta, carentes de normas internacionales para competir y erizados de normas nacionales frente a sus adversarios comerciales.

Oman señaló acertadamente no hace muchos años que un objetivo de la regionalización es debilitar los poderes rigidizados que se arraigan nacionalmente como un requisito para estimular las fuerzas de la competencia dentro de una región. La consecuencia es que el robustecimiento de las fuerzas competitivas internamente imprime mayor potencia y dinamismo a la competitividad regional en los mercados globales. "De esta manera la regionalización y la globalización pueden estar, y a menudo están, reforzándose mutuamente [...] Cuando la regionalización contribuye al robustecimiento de las fuerzas de la competencia los dos procesos tienden, en la práctica, a reforzarse mutuamente. En la actualidad la regionalización es, en parte, una respuesta a la globalización" (Oman, 1994:16).

Europa fue la que disparó el resurgimiento del regionalismo, particularmente en África y América Latina, al suscribir en 1957 el Tratado de Roma; después, a fines de los años ochenta, su decisión sin precedentes de profundizar la integración europea en la forma de un mercado único inauguró la época de las grandes agrupaciones, en primer lugar el Tratado de Libre Comercio de América del Norte (TLCAN) y la conversión de Estados Unidos (EU) a su posición actual de principal fuerza regionalizadora. A la fecha EU ha suscrito más de dos docenas de acuerdos comerciales con países en desarrollo y desarrollados (Australia y Canadá, entre otros). La Unión Europea no se ha quedado atrás y ha forjado hasta ahora el más extenso espacio regionalizado, que incluye ya países latinoamericanos.

Los acuerdos regionales y bilaterales de los países desarrollados persiguen la preservación de espacios geográficos de influencia y la promoción de sus intereses en sectores específicos como los textiles y el vestuario, la biotecnología, los productos farmacéuticos, las telecomunicaciones y las finanzas, entre otros; como también objetivos estratégicos como la seguridad de largo plazo del acceso a recursos energéticos y, en general, de materias primas.

Finalmente, en cuanto a los acuerdos Norte-Sur, que en muchos textos se les conoce como nuevo regionalismo (aunque el concepto se ha expandido considerablemente) se indican tres rasgos peculiares de los mismos. Se excluye la versión del nuevo regionalismo como acuerdos “entre países grandes y pequeños". Ése no es un rasgo original. La integración regional de países con notables asimetrías es un hecho muy conocido de antaño, incluida América Latina. 
Las tres características inconfundiblemente originales de los acuerdos Norte-Sur son los siguientes:

1. La tendencia de Estados Unidos y la Unión Europea a la regionalización con países en desarrollo y desarrollados de menor tamaño (Canadá o Australia son pequeños respecto de Estados Unidos; el conjunto de las naciones "en transición" en Europa lo son respecto de la Unión Europea);

2. El hecho de que la iniciativa ha partido de Estados Unidos y la Unión Europea y no a la inversa. Ciertamente ahora hay muchos países que tocan a la puerta de ambos, pero el ingreso es selectivo y la llave no la tienen los solicitantes. En América Latina a ningún gobierno le pasó jamás por la cabeza la posibilidad de suscribir un acuerdo de integración con Estados Unidos antes que el presidente George Bush padre lanzara en 1990 la "Iniciativa para las Américas".

3. En los acuerdos Norte-Sur, sobre todo los de Estados Unidos, si bien se rigen por el principio de la reciprocidad, son los países de menor tamaño relativo los que llevan a cabo de forma unilateral la casi totalidad de las reformas (Ethier, 1998). Ciertamente en algunos casos se hacen excepciones a la reciprocidad general, pero en honor a la verdad son concesiones aconsejadas por la prudencia, no se trata de ahorcar; pero ninguna de esas concesiones afecta en nada lo que es fundamental para el país "grande".

Finalmente, es usual que se recomiende al Sur celebrar acuerdos con el Norte con el fin de obtener mejores resultados que con los acuerdos Sur-Sur. En principio, el supuesto no tiene discusión, al menos en volúmenes de comercio. Sin embargo, las respuestas definitivas sólo pueden darse al analizar casuísticamente los diferentes convenios y no sólo su capítulo de Acceso a Mercados, en particular cuando se trata de acuerdos con Estados Unidos. En todo caso los resultados de las negociaciones se mejoran si los países que negocian con el Norte tienen un proyecto nacional y cuentan con políticas económicas bien concebidas, diseñadas y orientadas al desarrollo. Por sí sola la inversión extranjera no opera milagros. Lo confirma América Latina: "Con ingresos (de inversión extranjera) 13 veces superiores a los registrados en la década de los setenta, durante los noventa se evidencia una tasa de crecimiento promedio 50 por ciento menor" (Mortimore,1999).

\section{Regionalismo y multilateralismo: reconceptualizar la relación}

Al término de la Segunda Guerra Mundial los países victoriosos estaban bajo la fuerte impresión del desquiciamiento del comercio internacional en los años treinta, en 
virtud de las políticas excesivamente proteccionistas que se erigieron en equivocada respuesta a la Gran Depresión. El nuevo signo de los tiempos fue abrir los mercados, Estados Unidos se consideró predestinado para promoverlo pues tenía la cuota de capacidad productiva más grande del mundo. Europa y Japón estaban en ruinas y no eran mercados consumidores. El Plan Marshall salió al paso de la situación con la doble finalidad de abrir los mercados y de contribuir a que Europa se pusiera en pie, pues se le asignaba ser la zona de contención del poderío soviético.

Así se abrió un fecundo periodo de restablecimiento de la interdependencia económica mundial y su motor fue el comercio. Por esta razón se abrigó la idea de que se llegaría finalmente al establecimiento de un mundo unificado por el comercio, idea subyacente hasta el presente en el multilateralismo contemporáneo. La diferencia fundamental con nuestro tiempo es que gracias a la revolución de las tecnologías de la información y las comunicaciones se ha operado en gran escala la internacionalización de la producción y, en consecuencia, ha cambiado el orden de los factores inversión y comercio; ahora el principal catalizador de la aceleración de la integración económica global es el capital internacional (UNCTAD, 1997).

Frustrado el intento de crear una organización mundial del comercio, la opción fue suscribir a fines de 1947 el Acuerdo General sobre Aranceles Aduaneros y Comercio (GATT). Con el pasado muy presente se pensó que debía establecerse firmemente el principio de la no discriminación en el comercio mundial, y la mejor manera de conseguirlo fue la adopción de la cláusula de Nación Más Favorecida (NMF), y de conformidad con ese principio el Trato Nacional, como quedó asentado desde entonces en los artículos I y III.4 del GATT de 1947.

No obstante su carácter provisional y no institucional, el GATT cumplió eficazmente su papel como marco en el que Estados Unidos promovió la serie de rondas de negociación para restablecer el comercio mundial. Casi medio siglo después culminó con éxito la Ronda Uruguay, la más ambiciosa de la larga serie de negociaciones multilaterales, que dio lugar a la creación de la Organización Mundial de Comercio. Para el multilateralismo éste fue un paso de mayor importancia, pues el GATT fue un conjunto de normas sin un fundamento institucional, aplicado sobre una base provisional, mientras la OMC es una institución permanente con una estructura estable y su propia secretaría.

Resultados tan auspiciosos alentaron la suposición de que las excepciones al principio de no discriminación perderían atractivo para los países y que, en consecuencia, seguirían una tendencia de aproximación de sus normas a las de la OMC haciéndolas más compatibles, una compatibilidad que inútilmente pretendió realizar 
el "regionalismo abierto" (Bergsten, 1997; CEPAL, 1994 y 1996; Kuwayama, 1999). Tan complacidas suposiciones pusieron de manifiesto que los multilateralistas aún no comprendían por qué había excepciones al principio de no discriminación y por qué es posible anticipar su permanencia. Posiblemente tenían en cuenta sólo las negociaciones del pasado, pero en el desmantelamiento arancelario hubo un interés común de todos los países desarrollados en llevarlo a cabo, los intereses de las naciones en desarrollo tuvieron muy limitada participación y la que tuvieron fue imperceptible. No ocurre lo mismo con las excepciones a la no discriminación. Un breve repaso de su autorización acentuará las diferencias, pondrá de manifiesto en quiénes se ha pensado al concederlas y cuáles son los intereses que las han promovido, lo que dará lugar a preguntarse si es posible su extinción en un futuro previsible o lo contrario, su permanencia.

\section{Las exenciones}

$\mathrm{Al}$ crearse el GATT quedó asentado en su artículo XXIV el reconocimiento de las partes contratantes de que para aumentar la libertad de comercio debía favorecerse una integración mayor de las economías de las naciones mediante acuerdos libremente concertados y, en consecuencia, no debía impedirse el establecimiento de una unión aduanera ni el de una zona de libre comercio En el artículo se detallaron las condiciones a que estaría sujeta la autorización por las partes contratantes del establecimiento de ambas formas de integración económica.

El acuerdo constitutivo del GATT admitió además una segunda exención del cumplimiento de sus disposiciones, la contenida en el artículo XVIII, y su finalidad era apoyar el desarrollo de "las partes contratantes cuya economía sólo puede ofrecer a la población un bajo nivel de vida y se halla en las primeras fases de su desarrollo", y por su efecto se autorizó la protección arancelaria requerida para la creación de determinadas ramas de producción y establecer restricciones cuantitativas de las importaciones por motivos de balanza de pagos.

Si bien son de índole diferente de las anteriores, el Acuerdo General contiene otras medidas discriminatorias de las importaciones como las medidas antidumping del artículo VI, el Acuerdo Multilateral alcanzado en la Ronda Uruguay sobre medidas compensatorias cuando una de las partes contratantes otorgue subvenciones, y el Acuerdo Multilateral sobre Salvaguardias.

A las exenciones anteriores hay que sumar otras más; en primer lugar, el Tratamiento Especial y Diferenciado por el cual los países en desarrollo son exentos de cualquier requerimiento de reciprocar los beneficios que les acuerden las naciones 


\section{4}

ALFREDO GUERRA-BORGES

desarrolladas en las negociaciones multilaterales. De igual manera, en la Ronda Uruguay, suscrita como acuerdo único (single undertaking) y, por tanto, obligatoria en todos sus términos para todas las partes, en virtud del Tratamiento Especial se permitió a los países en desarrollo que su aplicación pudiera hacerse en plazos mayores o con mayores facilidades.

En segundo lugar, en 1971 se autorizó mediante un waiver el Sistema Generalizado de Preferencias (SGP) con el fin de que los países desarrollados pudieran otorgar a las naciones en desarrollo ventajas de acceso a sus mercados, dejando a la discreción de las potencias la designación de los beneficiarios, la selección de los productos y otras particularidades.

Finalmente, el Entendimiento del GATT de 1979, conocido por Cláusula de Habilitación, dio carácter permanente al SGP y reconfirmó para los países en desarrollo la noción de no reciprocidad en las negociaciones multilaterales.

\section{Significado de las exenciones}

¿Qué significado tienen las exenciones? ¿Qué intereses y reconocimientos trasluce el elaborado conjunto de exenciones a la cláusula NMF? El conjunto de ellas traduce ante todo el reconocimiento que desde un principio hicieron los países desarrollados de que las naciones en desarrollo no tienen, por razones históricas y estructurales profundas, capacidad para asimilar las consecuencias del libre comercio irrestricto como sí las tienen los primeros, que son los beneficiarios principales del libre comercio y sus principales promotores.

Ha habido reconocimiento de que los acuerdos comerciales regionales, explícitamente las uniones aduaneras y las zonas de libre comercio, contribuyen eficazmente a la liberalización comercial en la medida que lo promueven entre sí las partes contratantes sin daño a terceros países. Ha habido reconocimiento de que las naciones de menor desarrollo necesitan administrar las importaciones y su balanza de pagos en función de sus programas de desarrollo económico. Ha habido reconocimiento de la exclusión de los países en desarrollo del compromiso de aplicar en pie de igualdad con las naciones desarrolladas los acuerdos que se alcancen en negociaciones multilaterales.

\section{Conclusiones}

El 10 de septiembre de 2007 el director general de la OMC, Pascal Lamy, pronunció un discurso de apertura de la conferencia que había convocado sobre Multilaterización del regionalismo. En su discurso Lamy plantea una vez más la preocupación 
por la proliferación de los acuerdos regionales de comercio, esta vez por "la falta de equidad en las relaciones comerciales" (sic), pero también dos cuestiones interesantes: “¿Debemos replantear un poco nuestro enfoque de la cooperación comercial?”, y agrega: “[...] quisiera preguntar qué podría hacer la OMC para evitar que los aspectos negativos de los acuerdos regionales prevalezcan" (Lamy, 2007).

Por lo que se refiere a la inquietud manifestada por Lamy, hay que convenir que apunta en dirección equivocada. Es la falta de equidad en la economía mundial uno de los motivos para acogerse defensivamente a los acuerdos comerciales. La falta de equidad no proviene de la multitud de acuerdos, sino de las profundas desigualdades en el mercado internacional, de que los países en desarrollo acaten las normas de la OMC mientras las naciones desarrolladas mantienen múltiples apoyos y subsidios a su producción y sus exportaciones; proviene del gigantismo alcanzado por las empresas transnacionales y en particular su carrera de compras y fusiones transfronterizas de empresas cuyo "poder tentacular va estrangulando un sistema de producción y comercio que alguna vez, hace más de 100 años, pudo el liberalismo imaginar como de libre competencia" (Guerra-Borges, 2002).

En cuanto a si la OMC debe replantear su enfoque de la cooperación regional los hechos indican que en efecto debe replantearlo abandonando definitivamente la obsesiva pretensión de multilateralizar los acuerdos comerciales. El regionalismo ya llegó a su mayoría de edad y debe abandonarse todo condicionamiento a su existencia y a su operación; toda pretensión de tutelarlo, pretensión en que, por lo demás, la OMC hace años fue holgadamente sobrepasada. Regionalismo y multilateralismo son dos productos de la mundialización y cada uno tiene un papel que desempeñar en la economía internacional. El regionalismo no es una anomalía. El multilateralismo no es una panacea. Los dos tienen deficiencias innumerables y es mejor para la salud de la economía mundial que los superen, pronto o gradualmente, cada uno por su cuenta o en cordial cooperación.

De lo expuesto al repasar las exenciones en párrafos anteriores es obligado concluir que las exenciones no se han concedido por capricho, ni por conveniencias políticas o económicas coyunturales, sino por la admisión inexcusable de que la capacidad de adecuación a los cambios políticos y sociales y, en definitiva, técnicoeconómicos es extremadamente desigual de unos países a otros y requiere, por tanto, de un tratamiento desigual.

Debe hacerse además el reconocimiento del punto a que se ha llegado en la evolución del regionalismo y del multilateralismo institucionalizado después de 50 años y con posterioridad al fracaso de las negociaciones de la Ronda Doha. La proliferación 


\section{6}

ALFREDO GUERRA-BORGES

de acuerdos preferenciales, bilaterales y regionales de comercio, cuyo número ronda en la actualidad la cifra de 300, testifica que los países en desarrollo, y por razones diferentes las potencias comerciales, encuentran en el regionalismo una vía para la realización de programas que ahora y en el futuro previsible no tienen salida en la OMC. "El crecimiento de los bloques comerciales regionales [...] es uno de los más importantes desarrollos de las relaciones internacionales en años recientes" (World Bank, 2000:1). "El regionalismo es ahora una opción política para la mayor parte de los países y una característica permanente de las condiciones a que estará sometido el comercio internacional en el futuro previsible" (UNCTAD, 2005:3).

Del otro lado lo que cabe decir del multilateralismo es simplemente que cuando la OMC vio la luz en 1994 la cláusula de Nación Más Favorecida estaba ya muy debilitada. Así lo manifiesta la propia organización:

Casi cinco décadas después de la fundación del GATT, la cláusula NMF ya no es más la norma que rige; es casi la excepción [...] los mercados comunes, las áreas de libre comercio regionales y bilaterales, las preferencias y una interminable miscelánea de arreglos casi se ha llegado al punto en que el tratamiento NMF es un tratamiento excepcional. Ciertamente el término ahora podría ser mejor definido como Tratamiento de Nación Menos Favorecida" (OMC, 2004).

Así las cosas, pretender la multilateralización de los acuerdos que están exceptuados de las normas básicas de la OMC puede explicarse sólo porque perdura la concepción del multilateralismo de hace 50 años, sobrevive con el vigor de todas las idealizaciones y no se ha corregido la percepción minusvaluante de los acuerdos regionales que también tiene 50 años.

En cuanto a lo primero, el multilateralismo tal como hasta ahora se concibe es simplemente la vieja idea neoclásica de la preferencia por el desmantelamiento arancelario unilateral no discriminatorio, que se considera la opción óptima, visiblemente emparentada con la teoría clásica del comercio internacional de acuerdo con la cual el bienestar se eleva mediante el libre comercio, gracias a que puede hacerse una asignación óptima de los recursos, especializándose en lo que tenga costos comparativos menores. Posteriormente, Jacob Viner (1950), cuando sentó las bases de la teoría neoclásica de la integración con sus conceptos teóricos de la creación y la desviación de comercio, abrió la brecha de la teoría del subóptimo, en la que ubicó las uniones aduaneras y las zonas de libre comercio, y el GATT en su artículo XXIV.

En el actual estado de cosas uno puede preguntarse legítimamente por qué se persevera en la reafirmación de una supremacía de la OMC que en los hechos se ha 
perdido, y no se corrige el concepto minusvaluante de los acuerdos regionales que en la actualidad aportan más de 40 por ciento del comercio mundial, mientras que la OMC ha quedado, quien sabe por cuánto tiempo, como el guardián de los acuerdos de la Ronda Uruguay y del pasado, impotente para llevar adelante su cometido principal, las negociaciones multilaterales.

Se menciona de paso, para evitar un malentendido de las afirmaciones anteriores, que al hacer un balance del GATT y la OMC se expresa el reconocimiento del papel desempeñado por ambas; fue en el marco del GATT que se desmontó el andamiaje proteccionista de los años treinta y se restableció la liberalización del comercio en un nuevo ambiente; con la creación de la OMC el comercio internacional y la cooperación comercial mundial cuentan ahora con una institución especializada cuyo cometido es promover el comercio mundial; la guerra comercial de los años treinta ha sido sustituida por normas que regulan, en lo que cabe, la actuación de los Estados en el campo comercial internacional reduciendo su poder discrecional; $y$ ha abierto nuevos espacios a la actividad internacional de las empresas privadas. Por sucinto que sea este recuento es innegable que en su haber el GATT y la OMC tienen un activo muy sobresaliente.

Aunque se admita que no hay condiciones ni disposición de los Estados para operar en la OMC los cambios que le permitan adaptarse al mundo actual, remodelado por la globalización, la hipótesis es que la relación del regionalismo y el multilateralismo debe ser revaluada. Esta hipótesis la confirman positivamente los razonamientos y los hechos expuestos, de lo que se concluye que en adelante la obsesiva idea de la multilateralización del regionalismo debe ser definitivamente abandonada. Regionalismo y multilateralismo deben coexistir, lo que no significa que actúen como compartimentos estancos, sino como entidades que interaccionan, cada una con la representación que la realidad les conceda, no las ideas ya préteritas.

Parece que se puede terminar este texto con una formulación de Deblock: el debate contemporáneo gira en torno a la compatibilidad del regionalismo con el multilateralismo, "pero vista la amplitud de la ola regional, quizás fuera el tiempo de invertir el problema y preguntarse, no si el regionalismo es o no compatible con el multilateralismo, sino si el multilateralismo es todavía compatible con el regionalismo" (Deblock, 2003:9). 


\section{Bibliografía}

Bergsten, Fred, "Open Regionalism", The World Economy, vol. 20, núm. 5, 1997.

Buzan, Barry, "The Asia-Pacific: What sort of region in what sort of world?", en A. McGrew y C. Brook, editores, Asia Pacific in the New World Order, Londres y NuevaYork, Routledge, 1998.

CEPAL, Open regionalism in Latin America and the Caribbean: Economic integration as a contribution to the changing production pattern with social equity, Chile CEPAL, 1994.

, Panorama de la inserción internacional de América Latin, Chile, CEPAL 1996.

Deblock, Christian, Regionalisme, multilateralisme et nouvel ordre international. La zone de libre echange des Ameriques comme modèle institutionnel, París, 2003.

Dunning, John, Globalisation, economic reestructuring and development, UNCTAD, 1994.

Ethier, Wilfred, "Regionalism in a mulilateral world", Journal of Political Economy, vol. 106, Chicago, The University of Chicago, 1998.

, "The new regionalism", The Economic Journal, núm. 108, Londres, Royal Economic Society, 1998.

Fondo Monetario Internacional, Las perspectivas de la economía mundial, FMI, 1997.

Guerra-Borges, Alfredo, Globalización e integración latinoamericana, México, Siglo XXI Editores e Instituto de Investigaciones Económicas de la UNAM, 2002, p. 87.

Inotai, Andras, "Introduction", en Björn Hettne, Andras Inotai y Osvaldo Sunkel (eds.), National Perspectives on the New Regionalism in the North, vol. 2, Londres, Macmillan Press Ltd, 2000.

Katzenstein, Peter J., Regionalism in Comparative Perspective, Cornell University, ARENA Working Papers WP 96/1, 1996.
Kuwayama, Mikio, Open regionalism in Asia Pacific and Latin America: A survey of the literature, 1999.

Lamy, Pascal, Discurso en la apertura de la Conferencia sobre Multilateralización del Regionalismo, Ginebra, OMC, 2007.

Mistry, Percy, "The new regionalism: Impediment or spur to future multilateralization", en Bjorn Hettne, Andras Inotai y Osvaldo Sunkel (eds.), Globalization and the New Regionalism, vol. 1, Gran Bretaña, MacMillan Press Ltd., 1999.

Mortimore, MichaeL, "¿Contribuye la inversión extranjera al crecimiento económico?", Notas de la CEPAL, núm. 5, 1999.

OCDE, La tecnoligie et la economie: les relacions determinantes, París, OCDE, 1992.

Oman, Charles, The policy challenges of globalisation and regionalisation. The challenge for the developing countries, París, OCDE, 1994.

OMC, The future of the WTO: Addressing institutional challenges in the new millenium. Report by the Consultative Board to Director-General, Supachai Panitchpatki, 2004, p. 19.

Shahid, Burki y Guillermo Perry, "Towards Open Regionalism", en Trade: Towards Open Regionalism, World Bank Conference on Development in Latin America and the Caribbean, 1997.

ONU, World Investment Report, ONU,1992.

UNCTAD, Multilateralism and regionalism: The new interface, Ginebra, ed. Mina Mashayekhi y Taisuke Ito, 2005. 1997.

Trade and Development Report,

Winters, Allen, Regionalism versus multilateralism, World Bank, Policy Research Working Papers 1687, 1996.

World Bank, Trade Blocs, Oxford, Oxford University Press, 2000. 